\title{
Wir gratulieren: Paul Kaegbein zum 95.
}

https://doi.org/10.1515/bfp-2020-2094

Paul Kaegbein ist vor 95 Jahren am 26. Juni 1925 in Dorpat, Estland zur Welt gekommen. Dem Land seiner Jugend ist er bis heute treu geblieben: Das Ehrenmitglied der Baltischen Historischen Kommission ist für diese weiterhin bibliografisch tätig; die Paul-Kaegbein-Stiftung der BHK fördert Forscher und Forschungsprojekte $\mathrm{zu}$ baltischen Themen. Mit Baltica online legt er u. a. eine kontinuierlich aktualisierte Liste einschlägiger URLs vor. Sie sind ein Zeichen seiner ungebrochenen Arbeitsfähigkeit, die immer bewundert wurde: Auch auf den anstrengendsten Interkontinentalflügen sah man ihn seelenruhig in seine Papiere vertieft. Internationalität war immer ein besonderes Merkmal seiner Arbeit - und immer auch ein Merkmal der Zeitschrift BIBLIOTHEK - Forschung und Praxis, deren Idee bei einem Spaziergang am Rhein - es muss am 19. Mai 1976 gewesen sein - von einer DFG-Sitzung zur Bibliotheksforschung zurück ins Bad Godesberger Hotel entstanden ist. Für den im Vorjahr nach Köln berufenen neuen Ordinarius der Bibliothekswissenschaft und zugleich Direktor des Bibliothekar-Lehrinstituts des Landes Nordrhein-Westfalen war es genauso wie für mich als Badenwürttembergischen Bibliotheksplaner und Direktor der Ba- dischen Landesbibliothek ein wichtiges Anliegen, dass die neu in den Fokus gerückte bibliothekswissenschaftliche Forschung einen engen Praxisbezug haben sollte. Die Aufbruchstimmung wird in den programmatischen „Neuen Perspektiven der Bibliotheksforschung “ in Heft 1 der frisch gegründeten Zeitschrift deutlich sichtbar, die seit 1977 unterstützt von Klaus Saur als Verleger erscheinen konnte. Mit Hans-Joachim Kuhlmann, dem Direktor der Stadtbibliothek Essen als Drittem im Bunde, war ein weiteres Markenzeichen von BFP gesetzt: die volle Integration auch der Öffentlichen Bibliotheken.

Seither haben wir unterstützt von einer wachsenden Zahl kontinuierlich oder als Gäste mitwirkenden Herausgeber daran gearbeitet, den Modernisierungsschub des deutschen Bibliothekswesens immer neu zu unterstützen und Transformationsriemen für neue Ideen und Entwicklungen zu sein. Paul Kaegbein hat dazu wesentliche Beiträge geleistet; jetzt unterstützt er auch unser Ziel, die Zeitschrift in Zukunft Open Access erscheinen zu lassen.

Wir senden ihm zu seinem 95. Geburtstag unsere herzlichen Glückwünsche. Mögen ihm viele weitere Jahre in Gesundheit mit Lebens- und Arbeitsfreude geschenkt sein.

Elmar Mittler im Namen der Herausgeber 